\title{
A Parenting Intervention for Childhood Behavioral Problems: A Randomized Controlled Trial in Disadvantaged Community-Based Settings
}

\author{
Sinead McGilloway and Grainne Ni Mhaille
}

National University of Ireland, Maynooth

\author{
Mairead Furlong, Yvonne Leckey, and Paul Kelly
}

National University of Ireland, Maynooth

\author{
Tracey Bywater \\ University of York
}

Catherine Comiskey
Trinity College Dublin

\author{
Michael Donnelly \\ Queen’s University Belfast
}

\begin{abstract}
Objective: A community-based randomized controlled trial (RCT) was conducted in urban areas characterized by high levels of disadvantage to test the effectiveness of the Incredible Years BASIC parent training program (IYBP) for children with behavioral problems. Potential moderators of intervention effects on child behavioral outcomes were also explored. Method: Families were included if the child (aged 32-88 months) scored above a clinical cutoff on the Eyberg Child Behavior Inventory (ECBI). Participants $(n=149)$ were randomly allocated on a 2:1 ratio to an intervention group $(n=103)$ or a waiting-list control group $(n=46)$. Child behavior, parenting skills, and parent well-being were assessed at baseline and 6 months later using parent-report and independent observations. An intentionto-treat analysis of covariance was used to examine postintervention differences between groups. Results: Statistically significant differences in child disordered behavior favored the intervention group on the ECBI Intensity (effect size $=0.7, p<.001$ ) and Problem subscales (effect size $=0.75, p<.001$ ). Intervention effects on child hyperactive-inattentive behaviors and social competence, as well as parent competencies and well-being, were also found. Moderator analyses showed that the effects of the IYBP intervention on the primary child outcomes were not moderated by child or family demographic characteristics or risk factors. Conclusion: The results demonstrate the effectiveness of the IYBP in alleviating problem behavior among children and in improving well-being among families living in disadvantaged areas. The findings also highlight the importance of parental intervention in early childhood for parents and children most in need of support.
\end{abstract}

Keywords: child behavioral problems, conduct disorder, parent training, parenting, parent-child relationships

Conduct problems, such as aggressive, oppositional, and hyperactive-inattentive type behaviors, are common in early childhood and are becoming more prevalent (Collishaw, Maughan, Goodman, \& Pickles, 2004). Early childhood behavioral difficulties are highly predictive of a range of difficulties, including poor scholastic achievement (R. Reid, Gonzalez, Nordness, Trout, \& Epstein, 2002) and antisocial behavior and peer rejection (Ladd, Birch, \& Buhs, 1999) during childhood, as well as poor outcomes in adulthood, such as criminal behavior, poor employment prospects, and mental ill health (Colman et al., 2009; Fergusson, Horwood, \& Ridder, 2005).

Low levels of parental supervision and involvement and harsh and inconsistent discipline are particularly strongly associated with
This article was published Online First December 12, 2011.

Sinead McGilloway and Grainne Ni Mhaille, Department of Psychology, National University of Ireland, Maynooth, Kildare, Ireland; Tracey Bywater, Institute for Effective Education, University of York, York, England; Mairead Furlong, Yvonne Leckey, and Paul Kelly, Department of Psychology, National University of Ireland, Maynooth; Catherine Comiskey, School of Nursing and Midwifery, Trinity College Dublin, University of Dublin, Dublin, Ireland; Michael Donnelly, Centre of Excellence in Public Health, School of Medicine, Dentistry and Biomedical Sciences, Queen's University Belfast, Belfast, Northern Ireland.

This research was funded by the Atlantic Philanthropies, with additional support from the Dormant Accounts Fund. We extend a sincere thanks to Archways for their support and facilitation of this research and to all of the families who participated in the study. We also thank all of the community-based organizations and the parent group facilitators for their cooperation throughout the research process. We acknowledge with thanks the invaluable support and advice that we have received from the Expert Advisory Committee, including Judy Hutchings, Mark Dynarski, Patricia Del Grosso, Paul Downes, Tony Crooks, and Catherine Byrne. We also acknowledge the input of colleagues at the National University of Ireland, Maynooth, and the Church of Ireland College of Education.

Correspondence concerning this article should be addressed to Sinead McGilloway, Department of Psychology, National University of Ireland, Maynooth, Maynooth, Ireland. E-mail: sinead.mcgilloway@ nuim.ie 
the development of conduct problems (Shaw \& Winslow, 1997). Parental mental illness and disrupted family life, which may affect the quality of parent-child interactions, have also been associated with behavioral deviancy (Trapolini, McMahon, \& Ungerer, 2007). Parent behavior may mediate the link between risk factors such as difficult child temperament and the likelihood of developing conduct-disordered behavior (Paulussen-Hoogeboom, Stams, Hermanns, Peetsma, \& van den Wittenboer, 2008). All of these factors may be further compounded by exposure to high levels of socioeconomic disadvantage, which have been shown to increase the risk of developing childhood behavioral difficulties (Frick \& Morris, 2004; Wasserman et al., 2003).

Evidence-based parenting programs have been identified as an important early intervention strategy designed to improve child functioning, with the long-term goal of producing productive and well-adjusted adults (Barlow, Smailagic, Ferriter, Bennett, \& Jones, 2010; Brestan \& Eyberg, 1998). Several group-based parenting programs have been found to be effective in reducing problem behaviors and improving prosocial behavior in children (Furlong et al., in press; Kaminski, Valle, Filene, \& Boyle, 2008). Research also indicates that parenting programs can improve parenting competencies as well as their psychosocial health and overall family adjustment (Hutchings, Bywater, Daley, Gardner, et al., 2007).

Recent evidence suggests that parenting programs can be effectively incorporated into community-based services (Gardner, Burton, \& Klimes, 2006; Hutchings, Bywater, \& Daley, 2007). However, to date, most trials of parenting programs have been conducted in clinical settings (e.g., Larsson et al., 2009). Furthermore, reviewers have pointed out that only a small number of parenting program trials meet the methodological (Serketich \& Dumas, 1996) or clinical criteria for inclusion in meta-analyses aimed at exploring the clinical effectiveness of parenting programs (Furlong et al., 2010). For example, many trials in this area do not use adequate randomization procedures (e.g., Scott, Spender, Doolan, Jacobs, \& Aspland, 2001) and/or appropriate methods for dealing with incomplete or missing outcome data (e.g., Braet et al., 2009; Larsson et al., 2009); other studies do not include children with clinically significant conduct problems (e.g., Dionne, Davis, Sheeber, \& Madrigal, 2009; Patterson et al., 2002). These limitations may compromise the understanding of the clinical effectiveness of parenting interventions under real-world conditions.

Exploring the factors and/or conditions that may facilitate or attenuate the outcomes of parent training programs is also critical for intervention research and program development and delivery. For example, studies have shown that age and gender play an important role in outcomes, with males and younger children benefiting more from parent training than females or older children (Lundahl, Risser, \& Lovejoy, 2006; M. J. Reid, Webster-Stratton, \& Hammond, 2003). Conversely, socioeconomic disadvantage, disrupted family life, and parental psychopathology have been associated with poorer treatment outcomes in parent training (Reyno \& McGrath, 2006). The identification of subgroups whose members may respond differentially to parent training is important in highlighting the conditions under which optimal outcomes may be achieved in the delivery of community-based interventions (Gardner, Hutchings, Bywater, \& Whitaker, 2010).

This study involved a randomized controlled trial (RCT) evaluation of the effectiveness of the Incredible Years BASIC parent- ing program (IYBP; Webster-Stratton, 2005) for Irish parents of children with significant and persistent behavioral difficulties. Recent findings have indicated that $15 \%$ of Irish children experience considerable socioemotional and/or behavioral adjustment difficulties (Williams et al., 2009); this figure is comparable to figures from the wider literature, which suggest a prevalence of 10\%-20\% (Attride-Stirling, Davis, Markless, Sclare, \& Day, 2001; Emerson \& Einfield, 2010). Additional research suggests that almost one quarter of parents use harsh or coercive disciplinary strategies with their children (Halpenny, Nixon, \& Watson, 2009). This is important because children of parents who report more frequent use of physical and harsh forms of punishment are more likely to display problematic behaviors (Halpenny et al., 2009; Larzelere, Cox, \& Smith, 2010). Thus, a substantial proportion of families in Ireland and elsewhere may benefit from parent training interventions.

The IYBP is a short, 12-18 session, group-based intervention guided by behavioral and social learning principles and considered to be a model program for addressing conduct problems in early childhood (Mihalic, Fagan, Irwin, Ballard, \& Elliot, 2002; National Institute for Health and Clinical Excellence, 2007). Available evidence indicates that the IYBP leads to significant improvements in parenting skills and child adjustment (Gardner et al., 2006; Hutchings, Bywater, Daley, Gardner, et al., 2007; WebsterStratton, 1998; Webster-Stratton, Reid, \& Hammond, 2004). There are currently different versions of the IYBP, but it has been previously delivered and researched as a 12-session program. However, the current study was original, in that it involved the new 14-session program (Webster-Stratton \& Reid, 2010), which is an updated version of the original 12-week program; according to Webster-Stratton, the program developer, this is the current recommended protocol or dosage (C. S. Webster-Stratton, personal communication, June 8, 2011).

Our principal aim in this study was to assess the effectiveness of the IYBP for improving child behavioral and social adjustment, as well as parental competencies and well-being in disadvantaged community-based service settings. We hypothesized that (a) parent training would lead to improvements in the intensity and frequency of child behavioral problems, including child conduct disordered and hyperactive-inattentive behaviors; (b) there would be positive changes in children's social skills; and (c) the intervention would lead to improvements in parenting practices and parental stress and well-being. Potential moderators of parent training outcomes were also explored by assessing the role of key child, family, and social characteristics in influencing child response to treatment.

\section{Method}

\section{Participants and Study Setting}

Families were recruited to the study using existing service systems, including public health service waiting lists, local schools, community-based agencies, and self-referral. Participants were eligible if the primary caregiver rated their child (aged 32-88 months) above the clinical cutoff on either the Intensity subscale (Intensity score $\geq 127$ ) or the Problem subscale (Problem score $\geq$ 11) of the Eyberg Child Behavior Inventory (ECBI; Eyberg \& Pincus, 1999). This cutoff has been used in similar research and is considered to indicate potentially significant psychopathology 
(Hutchings, Bywater, Daley, Gardner, et al., 2007). Parents also had to be willing and able to attend the program. In total, 149 families were eligible and agreed to participate in the research. At follow-up, 137 parents were retained in the trial (see Figure 1).

The intervention was delivered in community-based organizations or Family Resource Centres that provide statutory-funded, individual or group services and support for vulnerable families who experience difficulties, such as socioeconomic disadvantage, social isolation, mental health issues, substance misuse, community conflict, and domestic violence. Facilities include talks, activities, workshops, children's groups, individual advice and support, assessments, and child care for preschool children. These centers are located in four urban areas that are designated disadvantaged according to information on demographic profile, social class composition, and labor market situation (Haase \& Pratschke, 2008).

\section{Randomization, Allocation Concealment, and Blinding}

Participants were blindly allocated on a 2:1 basis, using a computer-generated random number sequence, to a parent training intervention group $(n=103)$ or a waiting-list control group $(n=$
46). This ratio results in a small reduction in statistical power but allows for the inclusion of a larger intervention group, which is ethically desirable in effectiveness evaluations conducted in community-based settings. The unit of randomization was the parent-child dyad and participants were block randomized by area to ensure that parents attended the program in their locality.

Randomization was carried out by an independent statistician who was not involved in data collection. Participant allocation was subsequently conveyed through private correspondence to an administrator who informed participants of their treatment allocation. Child age and gender were not restricted in randomization. Post hoc analyses revealed no significant differences between intervention and control groups with respect to age ( $p=.19)$. Although there were proportionately more boys in the control group (31/46; $67 \%)$ compared with the intervention group (60/103; 58\%), this difference was not statistically significant ( $p=.14)$. Concealment of the allocation sequence was ensured by randomizing participants after they had been recruited and had completed baseline assessments. Researchers were unaware of group allocation and parents were asked not to inform researchers at follow-up assessment as to whether they had taken part in the program.

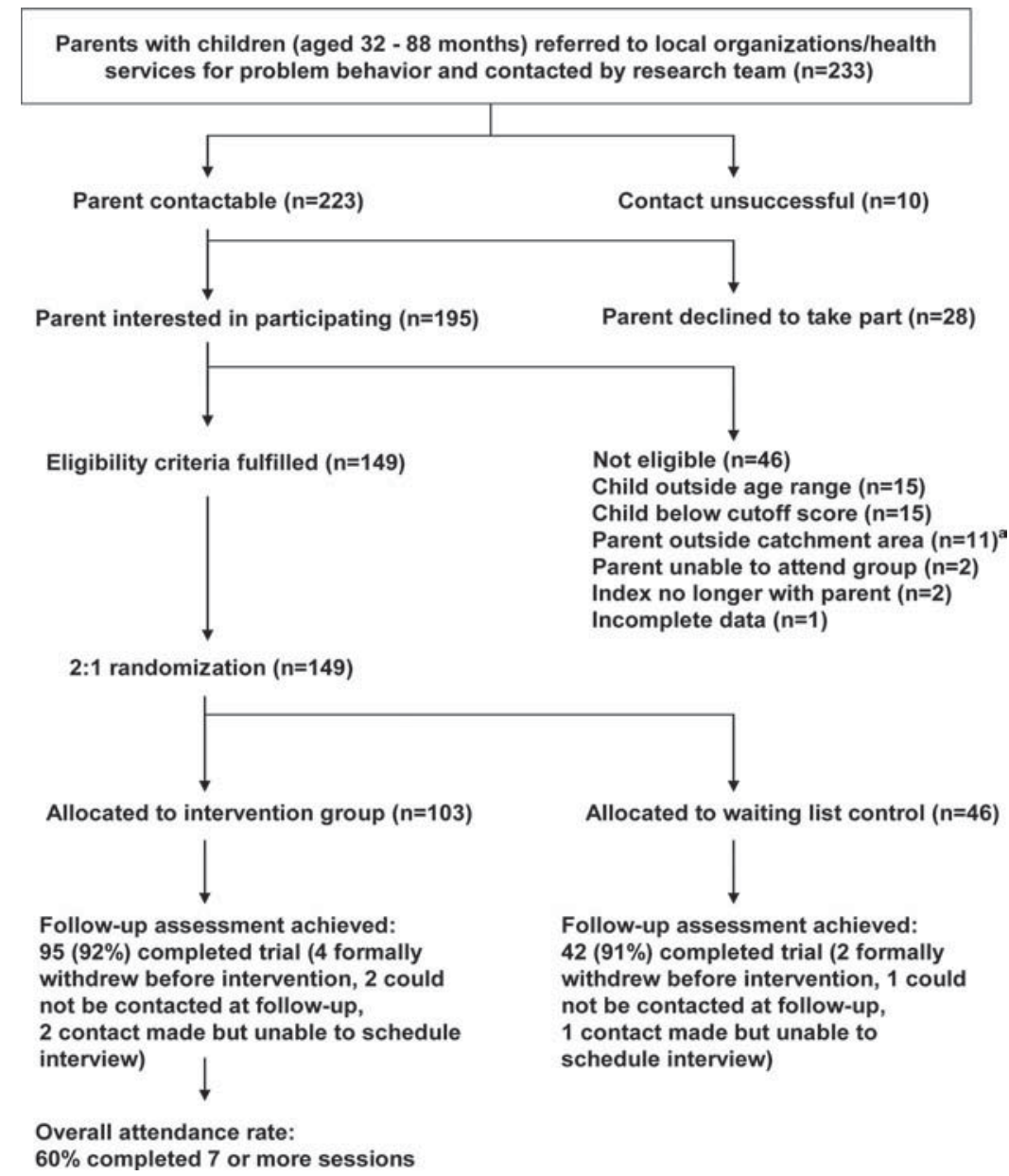

Figure 1. Consolidated Standards of Reporting Trials (CONSORT) diagram: Sample recruitment and attrition.

${ }^{a}$ Parents were subsequently offered parent training within their locality. 


\section{Procedure}

Information sheets were administered to referred families and written informed consent was provided by parents and guardians of participating children. Two cohorts of parents were recruited during a 6-month period. Baseline assessments for the first cohort of parents $(n=53)$ were carried out in February and March of 2008 with 6-month postbaseline follow-up assessments undertaken in July and August of the same year. The second cohort $(n=96$ parents) was interviewed in July and August of 2008 with subsequent follow-up assessments in January and February of 2009. At both time points, data were collected from one parent only, most of whom were mothers (143 mothers, six fathers). Parents in the intervention group received the IYBP after baseline assessment. The 6-month follow-up assessments took place approximately three months after intervention completion. The assessment of treatment effects at this time point did not indicate how participants fared immediately posttreatment. However, the intervening period provided reasonable time for parents to implement new parenting skills and to allow any child behavior changes to emerge. Control group parents were offered the IYBP after the 6-month follow-up. Participants were provided with a small payment after both the baseline and the follow-up assessments as a token of thanks for their participation in the research. No financial incentive was offered for taking part in the program itself.

\section{Measures}

Parents provided demographic and background information on their families and children. Psychometrically robust parentreport measures and independent observations were used to provide a comprehensive assessment of child behavior and social competencies, as well as parenting skills and well-being. The internal consistency of all scales was calculated on baseline data using Cronbach's alpha. Measures were administered by researchers (who were unaware of allocation) either in participants' homes or in a local family center.

Child behavior measures. The ECBI (Eyberg \& Pincus, 1999) was used as the primary outcome measure of child problem behavior. This screening tool, which is widely used in clinical practice and intervention studies, consists of two subscales that elicit parents' perceptions of 36 problem behaviors. The Intensity subscale comprises a 7-point Likert-type scale that measures how frequently each behavior occurs; the Problem subscale elicits information on the number of problem behaviors exhibited by the child, as well as a yes-no response as to whether the parent considers the child's behavior to be problematic ( $\alpha$ s $=.89$ and .87 for the Intensity and Problem subscales, respectively). ECBI normative data, based on a sample of children in a southeastern region of the United States $(n=798)$, indicate a mean score on the Intensity scale of $96.6(S D=35.2)$ and a mean score on the Problem scale of 7.1 ( $S D=7.7$; Eyberg \& Pincus, 1999).

Additional secondary measures were used to enhance sample description and to evaluate the intervention outcomes. The Strengths and Difficulties Questionnaire (Goodman, 1997) was used to assess child problem behavior and socioemotional wellbeing. This 25-item measure consists of five subscales relating to emotional symptoms, conduct problems, hyperactivity, peer problems, and prosocial behavior $(\alpha=.77)$. The scores on each subscale (except the Prosocial scale) may be summed to generate a total difficulties score for use in the analysis. The Conners Abbreviated Parent Rating Scale (Conners, 1994) provided a brief, 10-item measure of hyperactive-inattentive behaviors $(\alpha=.86)$ including restlessness, overactivity, emotional reactivity, and inattention. The Social Competence Scale (Corrigan, 2002) is a brief 12-item scale that assesses child social functioning, including emotional self-regulation and prosocial behaviors $(\alpha=.86)$. Typical items are "Your child shares things with others" or "Your child can calm down when excited or all wound up." Respondents are asked to rate the extent to which this statement reflects their child's behavior on a 5-point Likert-type scale.

Parental well-being measures. Levels of parental psychopathology and dysfunctional parent-child interactions were assessed to determine whether the intervention had led to any changes in parental distress and competency. The Parenting Stress IndexShort Form (Abidin, 1995) was used to obtain an overall measure of parent stress and functioning $(\alpha=.93)$. The scale comprises 36 items that measure the distress experienced by parents in their parenting role as well as dysfunctional parent-child interactions. The 21-item Beck Depression Inventory (Beck, Ward, Mendelson, Mock, \& Erbaugh, 1961) was also used to assess the overall prevalence and severity of depressive symptoms and behaviors among parents $(\alpha=.93)$.

Observational measure. The Dyadic Parent-Child Interactive Coding System - Revised (Robinson \& Eyberg, 1981) provided an independent observational measure of parent-child interactions and behaviors based on a 30-min observation period (in 5-min intervals). The coding system comprises 21 parent behavior categories (e.g., commands, questions, praise, positive affect, and physical behaviors) and seven child behavior categories (e.g., destructive and physically negative behaviors, smart talk, crying, and positive affect). Coding is continuous and is based on the frequency of a given behavior during parent-child interaction.

Summary variables of observational data were created for analysis. Child problem behavior represents the aggregate of frequency counts for aversive child behaviors, including destructive and aggressive behaviors (e.g., throwing items or hitting, shouting, crying, whining, and smart talk); child positive behavior consists of the summed counts of physically and verbally warm or positive behaviors. Positive parenting, comprising eight parent behavior categories, represents the summed frequency counts for use of praise and encouragement and positive physical behaviors toward the child (e.g., displays of affection). Critical parenting comprises three parent behavior categories, including the use of negative commands, critical statements, and physically negative behaviors (e.g., snatching an item away from the child).

Live observations were carried out mainly in the participants' homes while the parent and child engaged in play (e.g., doing a jigsaw puzzle, painting a picture, playing with toys). Parents were instructed not to interact with the observer and to continue with normal activities for the duration of the observation. They were also asked not to view television or play computer games. A number of observations were carried out in a community center ( $n=22 ; 12$ at baseline and 10 at follow-up) to facilitate parental participation. Observations were conducted at both baseline and follow-up for the second cohort of parent participants only (i.e., $54 \%$ or $80 / 149$ of the total sample; 56 intervention, 24 control). It was not possible to conduct observations during the first wave of 
participant recruitment because of observational training and service delivery timetabling constraints. Observers were unaware of participant treatment allocation and all received 5 days of intensive training. Once reliability with the primary coder was achieved, it was subsequently maintained by means of team coding meetings, during which videotaped parent-child interactions and practice observations were coded to ensure standardized coding. In total, $20 \%$ of all home and center observation visits were attended by two coders who coded simultaneously to assess agreement and interrater reliability. Reliability checks were conducted at both baseline and follow-up; an average interrater agreement of $70 \%$ is deemed reliable according to the Dyadic Parent-Child Interactive Coding System—Revised manual (Robinson \& Eyberg, 1981).

\section{Power Analysis}

A power analysis was undertaken to determine sample sizes sufficient to register significant change. A minimum reduction of 25 and a maximum reduction of 29 in the mean score on the ECBI Intensity subscale were considered significant, in line with previous studies (Hutchings, Bywater, Daley, Gardner, et al., 2007). Therefore, to achieve an effect size of 0.8 and allowing for a dropout rate of $18 \%$, a total sample size of 144 participants was recommended.

\section{Intervention}

The IYBP is a collaborative-based intervention that uses group discussions and role plays in combination with video material to illustrate various parenting and discipline strategies. Program topics include play, attention and involvement, listening, problem solving, praise, incentives, and limit setting and other nonaversive discipline strategies. The program promotes positive parenting techniques, such as child-directed play and encouragement, to foster child cooperation and strengthen parent-child relationships. Child problem behaviors are addressed by encouraging parents to reinforce positive prosocial behavior and to use nonaversive discipline strategies (e.g., time-out) to tackle aversive or inappropriate behaviors. Parents practice the new tasks and techniques at home and provide feedback at the next weekly session.

Treatment delivery. Nine intervention groups, each with approximately 11-12 participants, were delivered in weekly 2-hr sessions in several locations in a mideastern region of Ireland. Both participant cohorts received the 14-session intervention. However, because of time constraints, the 14 sessions were delivered over a 12-week period for the first cohort. Group sessions were held at a time and location that suited the participants. Parents also received a weekly support call from the group leader throughout the course, and follow-up sessions were delivered in the event that parents were unavailable to attend on any particular week. Free transportation, crèche facilities, or financial reimbursement for child care and refreshments were provided for the participants to encourage attendance. Partners were also encouraged to attend. Children did not receive any intervention. All training programs (including those that were later offered to participants in the waiting-list control group) were supported financially by Archways, a charitable community-based organization that supports the implementation and rollout of Incredible Years (IY) training and other evidence-based family interventions in Ireland. Two Archways staff are also fully accredited IY group facilitators/leaders.

Treatment integrity and fidelity. The treatment groups were facilitated by two persons who had received a minimum of three days of training in the context and techniques of the intervention. Group facilitators worked in the centers where the program was being delivered and had varied backgrounds including psychology, counseling, education, or related fields. All 11 group facilitators and leaders had prior experience in delivering the IYBP in community-based settings; three had achieved full accreditation in delivering the IYBP, whereas the remainder were working toward accreditation during the course of the study. The accreditation process involves rigorous independent assessments and regular reviews of delivery performance. During course delivery, all group facilitators received weekly supervision and support from a certified independent IY trainer and attended weekly meetings to assess progress and address issues that may have arisen during group sessions. Group sessions were videotaped and randomly reviewed by a certified trainer to evaluate treatment delivery.

Implementation fidelity was monitored by means of facilitatorcompleted self-evaluation checklists. A Leaders' Weekly Checklist (Webster-Stratton, Kolpacoff, \& Hollinsworth, 1988) was completed by group facilitators after each weekly session to check and record that they had covered all prescribed material (e.g., showed vignettes, covered relevant topics, checked homework). The results showed that $90 \%$ of all material had been covered across the 14 sessions. According to group facilitators, parents also completed or attempted their homework activities for $73 \%$ of the 14 sessions and had partial completion of homework $25 \%$ of the time. Similar measures of treatment fidelity have been reported elsewhere (e.g., Kling, Forster, Sundell, \& Melin, 2010). The group facilitators further reported that, of those parents who attempted to implement the skills at home, $80 \%$ did so with some success on a weekly basis, whereas $21 \%$ did so with total or almost total success. There was no validated independent measure of facilitator adherence to the intervention protocol, nor was the quality of program delivery objectively assessed.

Treatment attendance. Approximately three quarters (76\%) of the first cohort of participants attended seven or more sessions (mean attendance $=10.8$ sessions) compared with half $(52 \%)$ of the second cohort (mean attendance $=6.6$ sessions). In total, $31 \%$ of participants attended three or fewer sessions. The reasons for lack of program engagement were explored in a separate qualitative substudy that ran in parallel to the main RCT and that included a small subsample of parent participants $(n=8)$ who attended fewer than five sessions. Reasons for nonengagement included mainly practical or circumstantial barriers to program attendance (e.g., illness, change in employment status), although a small number of parents expressed dissatisfaction with the ethos of the course $(n=2)$ and concerns around invasion of privacy $(n=2$; Furlong \& McGilloway, in press).

\section{Analysis}

A strict intention-to-treat analysis was carried out whereby all participants were included in the analysis regardless of program attendance. No change from baseline was assumed for participants who were lost to follow-up. An analysis of covariance (ANCOVA) was carried out to examine postintervention differences between 
conditions on parent-report and observational measures, controlling for baseline score and intervention status. In this study, participants were nested within parent training groups. Group effects, such as facilitator differences or disparities in family characteristics, may have a potentially biasing effect. Therefore, parent training group (i.e., the different parent training groups to which participants were allocated) was also included as a covariate to account for potential variances at the group level (Varnell, Murray, Janega, \& Blitstein, 2004). A per protocol analysis was undertaken in parallel; this excluded only those participants who were lost to follow-up (no parents were excluded on the basis of intervention attendance).

Observational data were analyzed using the last observation carried forward for those who did not complete observations at follow-up. A secondary analysis of observational data was also carried out, excluding only those who were lost to follow-up. Interrater reliability, as measured by intraclass correlation coefficients for summary variables, showed high consistency (child problem behavior $=.88$, child positive behavior $=.97$, positive parenting $=.94$, critical parenting $=.90$ ). Square root transformations were used for purposes of analysis as observational variables were not normally distributed. Effect sizes for the ANCOVA were calculated using Cohen's guidelines whereby an effect size of 0.2 denotes a small effect, 0.5 a medium effect, and 0.8 a large effect of the intervention (Cohen, 1988).

\section{Results}

\section{Participant Characteristics}

The baseline characteristics of families, including those who were lost to follow-up, are shown in Table 1. Most participants were socially and economically disadvantaged when compared with average Irish norms (Central Statistics Office, 2006a, 2006b). At baseline, a constellation of co-occurring child difficulties was reported by parents, including externalizing, aggressive, and oppositional behaviors; high levels of hyperactive behaviors; and social skills deficits. Child participants were at risk of serious psychological distress, including the development of conduct disorder (CD). Risk factors for CD include single parenthood, teenage parenthood, parental depression, family poverty, and parental history of drug abuse or criminality (Webster-Stratton, 1998). The number of risk factors experienced by a child has been shown to increase the likelihood of developing CD (Loeber \& Farrington, 2001). In the current study, a risk factor score ranging from 0 to 5 was calculated on the basis of the above factors; $60 \%$ of participants (90/149) obtained a risk factor score of 2 or more.

Statistical analyses (chi-square and two-sample $t$ tests) indicated no significant differences between intervention and control group participants with respect to any baseline characteristics. Further analyses were conducted to examine differences between those retained in the study and those lost to follow-up. No significant differences were found between the two groups, with the exception that children of parents lost to follow-up obtained statistically significantly higher scores on the Social Competence Scale.

\section{Intervention Outcomes}

The intention-to-treat analysis revealed statistically significant between-group differences in child problem behavior. A large effect of the intervention on child behavioral adjustment was found on both the ECBI Intensity and Problem subscales. Betweengroup, postintervention differences in child behavior were also found in the analyses of our secondary measures. The results of the ANCOVA indicated significant intervention-control group differences on the Strengths and Difficulties Questionnaire total diffi-

Table 1

Demographic Characteristics at Baseline

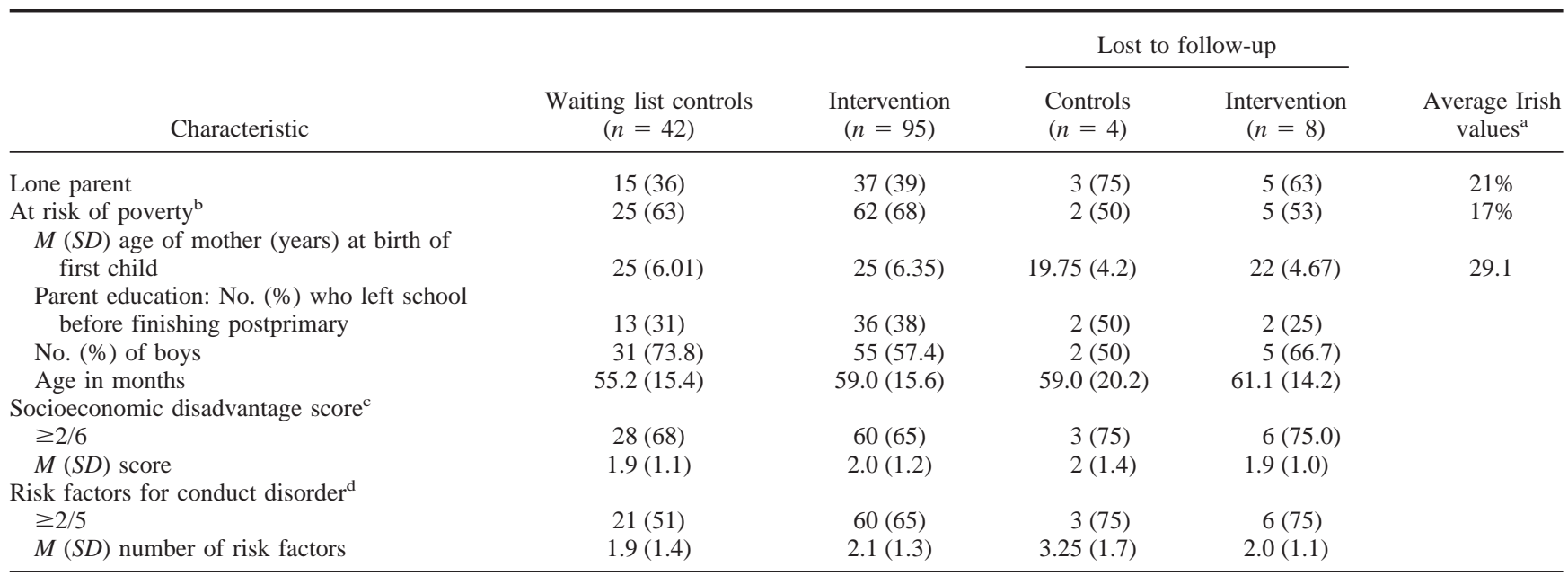

Note. Unless otherwise noted, the numbers provided are frequencies (\%). There were no significant differences between intervention families who remained in the study and those lost to follow-up (based on chi-square and two-sample $t$ tests).

${ }^{a}$ Data are from the 2006 Census (Central Statistics Office, 2006a). ${ }^{\text {b }}$ The European Union survey of income and living conditions categorizes an equivalized income of $€ 202.49 /$ week (approximately \$279/week) as the threshold for risk of poverty (Central Statistics Office, 2006b). ${ }^{\mathrm{c}}$ Employment status, parental status (lone vs. married or cohabiting), size of family, parental education, quality of housing, and levels of criminality in the participants' area of residence. $\quad$ d Single parenthood, teenage parenthood, parental depression, family poverty, and parental history of drug abuse or criminality. 
culties scores. Significant intervention effects were also found at follow-up on parent-reported levels of hyperactivity and inattention as measured by the Conners Abbreviated Parent Rating Scale and on prosocial behavior as measured by the Social Competence Scale. Analysis of observed child positive behavior did not show a statistically significant effect of the intervention, although there was a significant difference in observed child problem behavior for the intervention condition when compared with the control condition (see Table 2).

Significant differences between the intervention and control groups on frequency counts of critical parenting indicated that the intervention group parents used significantly fewer aversive parenting strategies at follow-up when compared with their control group counterparts. Significant effects of the intervention on both parental stress levels (as measured by the Parenting Stress Index) and parental depression (as measured on the Beck Depression Inventory) were also found when compared with the control group (see Table 3).

\section{Moderator Analysis}

Potential moderators of intervention effects on child conduct problems were examined in the intention-to-treat sample, using multiple regression on the follow-up data for the primary child outcome measure. Moderator effects on both subscales of the ECBI were examined. Thus, postintervention scores on the ECBI Intensity and Problem subscales were used as the dependent variables. Five key child and family variables, which were measured at baseline, were examined as potential moderators: child age, male child gender, being at risk of poverty, socioeconomic disadvantage, and risk factors for CD (see Table 1). A separate regression was conducted for each potential moderator, and all analyses controlled for baseline conduct problems. In Step 1, baseline ECBI scores, intervention status, and the potential moderator were entered. In Step 2, potential moderator effects were explored by introducing an interaction term (Potential Moderator $\times$ Intervention) into the regression model. Effect sizes for moderators were based on changes in the multiple correlation due to the introduction of the interaction term in the second step of the regression analyses (Jaccard \& Turrisi, 2003). The results showed no significant moderator effects on child problem behavior outcomes as measured by the ECBI Intensity and Problem subscales; this implies that any postintervention benefits for the children involved in this study occurred regardless of child and family demographic characteristics or risk factors (effect size $\left[\Delta R^{2}\right]=0$ for all potential moderators).

\section{Discussion}

The findings support the study hypotheses and highlight the effectiveness of the IYBP as an intervention for the early onset of behavioral problems in young children when implemented in community-based services. Although almost two thirds (63\%) of the families in the current study were exposed to multiple risk factors, the parenting intervention had a positive impact on child conduct problems, hyperactive behaviors, and social skills. Baseline mean scores on behavioral measures indicated that children were classified as at risk for future CD and delinquency but, at follow-up, the children in the intervention group were, on average, below the cutoff for clinical concern on the ECBI, the primary outcome measure.

Encouragingly, child behavior outcomes were not moderated by child characteristics, risks for $\mathrm{CD}$, or socioeconomic risks or disadvantage. Previous research has indicated that family adversity, in particular, can diminish the outcomes of parent training (Lundahl et al., 2006; Reyno \& McGrath, 2006). However, the current study findings indicate that children of families who experience adversity derived considerable benefits from parent training. These results are in keeping with a small number of studies that have found that the IYBP intervention positively influenced child behavior across a range of moderating variables (e.g., Beauchaine, Webster-Stratton, \& Reid, 2005; Gardner et al., 2010).

Previous research has identified changes in positive parenting as a key mediator of improved child behavior (e.g., Gardner et al., 2006, 2010), although the findings from the current study were not significant in this respect. However, prior research has highlighted reductions in critical parenting as a significant lever for improvement in child behavior (e.g., Beauchaine et al., 2005). Likewise, our findings show that there were significant postintervention improvements in critical parenting in the intervention group. Intervention effects on parent-reported stress and levels of depression were also found, thereby suggesting improvements in parental psychosocial functioning.

These findings support the general utility of parenting programs in real-world, community-based settings and services as a means of promoting parenting competency and overall family adjustment. Moreover, parenting programs can assist families who experience high levels of socioeconomic disadvantage while promoting positive behavior in children who are at risk of poorer outcomes into adolescence and adulthood. The cost implications of these programs are also an important additional consideration, and a separate cost-benefit analysis of the IYBP program, carried out in parallel to the current study, is reported elsewhere (O’Neill, McGilloway, Donnelly, Bywater, \& Kelly, in press).

\section{Comparison With Other Research}

This study is the first RCT evaluation of an updated version of the IYBP intervention. Previous research has evaluated shorter 9and 12-session interventions (Hutchings, Bywater, Daley, Gardner, et al., 2007; M. J. Reid, Webster-Stratton, \& Baydar, 2004), whereas a smaller number of studies have evaluated a longer 20to 22-session program (Webster-Stratton et al., 2004). Despite these differences in treatment length, the effects of the intervention in the current study are consistent with effect sizes reported in other IYBP trials. The findings from our study, which was carried out in urban settings, are comparable with those of a rural-based study in Wales (Hutchings, Bywater, Daley, Gardner, et al., 2007) and clinical-based work in Norway (Larsson et al., 2009). For example, the Welsh team reported moderate and large effect sizes of 0.63 and 0.89 on the ECBI Problem and Intensity subscales, respectively (Hutchings, Bywater, Daley, Gardner, et al., 2007). Comparable effect sizes, indicating a consistent benefit of the parenting intervention for child conduct problems, are reported here. Our study further indicates more substantial effects of the IYBP intervention for child hyperactivity and social competence. Notably, some of the above studies were undertaken within the context of integrated, multidimensional, community-led early 


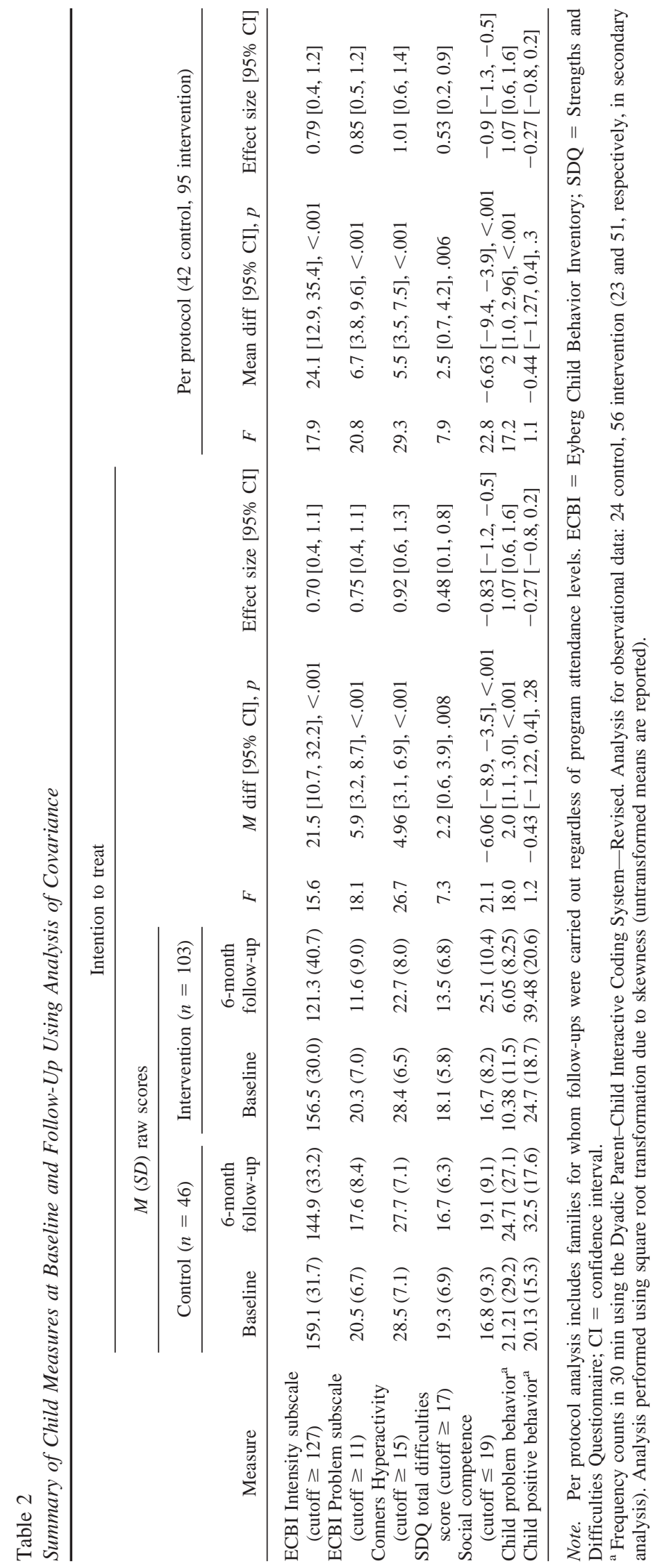


childhood initiatives (e.g., Sure Start in the United Kingdom and Head Start in the United States). However, the current trial was carried out in disadvantaged areas in Ireland, in the absence of any such national initiatives and within a context where other family services were limited, thereby reinforcing the potential utility of stand-alone parenting programs for at-risk families in the longer term.

\section{Study Strengths}

The key strengths of this study, which was the first to assess the effectiveness of the new 14-week IYBP, include the use of mixed methodologies and close adherence to the high-quality practices recommended for RCTs (Schulz, Altman, \& Moher, 2010). A sample-size calculation was conducted to ensure adequate statistical power, and strict randomization and blinding procedures were also applied. An intention-to-treat principle for incomplete or missing data was implemented to ensure that the clinical effectiveness of the program, when implemented in a real-world or community-based setting, was not overestimated (Hollis \& Campbell, 1999). A comprehensive error audit, conducted to ensure high-quality data, yielded an error rate for data input of less than $0.1 \%$. Subjective parental report was supplemented and amplified with more objective live observations of behavior, which were carried out by trained researchers; interrater reliability on this component of the study was also very high. Study attrition was low and those who were lost to follow-up did not differ from those who remained in the study in terms of demographic characteristics or child problem behaviors.

\section{Study Limitations}

The study also had a number of limitations. The observational findings were limited to just over half of the main sample because of timetabling constraints. It is also unclear why the intervention group participants had fewer negative behaviors at baseline than did their control group counterparts. This variation in observed behaviors was not attributable to the overall level of observed parent-child interaction or to baseline levels of child behavior problems. The number of boys in the control group in this study marginally also outweighed those in the intervention group. These differences, although statistically nonsignificant, may have had a biasing effect on outcomes and may compromise, to some extent, the generalizability of the findings.

Although a number of procedures were put in place to support intervention fidelity and facilitator self-reported fidelity was satisfactory, no independent verification of treatment adherence or assessment of the quality of program delivery was carried out (e.g., by clinicians, raters, or observers). The relatively low program attendance of $60 \%$, when compared with $83 \%$ in Hutchings, Bywater, Daley, Gardner, et al. (2007) and 88\% in Webster-Stratton (1998), was unexpected, although families who experience greater social and economic adversity are generally considered more difficult to engage in intervention and prevention programs (Baydar, Reid, \& Webster-Stratton, 2003). Therefore, it is likely that the attendance rates in the current study may have been negatively affected by the large proportion of participants who were experiencing significant socioeconomic disadvantage, especially the sec- 
ond cohort that included parents from a particularly highly disadvantaged inner-city area.

\section{Study Implications and Directions for Future Research}

This study, one of the first within a European context, focused on a high-risk sample recruited from real-world urban settings and showed significantly improved child and parent outcomes following a parenting intervention delivered by regular, communitybased service staff. The findings reported here support the importance of early childhood intervention and the utility of evidencebased parenting programs in community-based services in different cultural contexts and in settings characterized by high levels of social disadvantage. This work is an important step in the development, evaluation, and delivery of empirically validated interventions for vulnerable young children with conduct problems and their families. These findings should serve to guide future policy and practice decisions for governments and practitioners who are considering investing in and/or delivering the IYBP program for children with behavioral problems in disadvantaged communities across different geographical and cultural contexts.

Participants in the current trial were referred to the IYBP by means of self-referral and existing service systems; this indicates, at least in part, the potential for program sustainability into the future. However, if evidence-based parenting programs, such as the IYBP, are to be widely available and successful in the longer term, a number of other factors need to be in place, including the availability of willing and appropriately trained facilitators, ongoing monitoring of intervention delivery, and the availability of adequate administrative and financial support for program implementation. Thus, future research should continue to explore the effectiveness of parenting programs in community-based services, as well as the long-term outcomes for service users. Factors that contribute to program attendance in community settings and mediators of treatment response should also be explored. Such research would help to highlight ways in which highly vulnerable parents might be encouraged to engage with programs such as the IYBP and how optimal outcomes might best be achieved for all families in need of support.

\section{References}

Abidin, R. R. (1995). Parenting Stress Index (3rd ed). Odessa, FL: Psychological Assessment Resources.

Attride-Stirling, J., Davis, H., Markless, G., Sclare, I., \& Day, C. (2001). 'Someone to talk to who'll listen': Addressing the psychosocial needs of children and families. Journal of Community \& Applied Social Psychology, 11, 179-191. doi:10.1002/casp.613

Barlow, J., Smailagic, N., Ferriter, M., Bennett, C., \& Jones, H. (2010). Group-based parent-training programs for improving emotional and behavioural adjustment in children from birth to three years old. Cochrane Database of Systematic Reviews, 2010(3), Article CD003680. doi:10.1002/14651858.CD003680.pub2

Baydar, N., Reid, J. M., \& Webster-Stratton, C. (2003). The role of mental health factors and program engagement in the effectiveness of a preventive parenting program for Head Start mothers. Child Development, 74, 1433-1453. doi:10.1111/1467-8624.00616

Beauchaine, T. P., Webster-Stratton, C., \& Reid, J. M. (2005). Mediators, moderators, and predictors of 1-year outcomes among children treated for early-onset conduct problems: A latent growth curve analysis. Jour- nal of Consulting and Clinical Psychology, 73, 371-388. doi:10.1037/ 0022-006X.73.3.371

Beck, A. T., Ward, C. H., Mendelson, M., Mock, J., \& Erbaugh, J. (1961). An inventory for measuring depression. Archives of General Psychiatry, 4, 561-571.

Braet, C., Meerschaert, T., Merlevede, E., Bosmans, G., van Leeuwen, K., \& de Mey, W. (2009). Prevention of antisocial behavior: Evaluation of an early intervention program. European Journal of Developmental Psychology, 6, 223-240. doi:10.1080/17405620601033194

Brestan, E. V., \& Eyberg, S. M. (1998). Effective psychosocial treatments of conduct-disordered children and adolescents: 29 years, 82 studies, and 5,272 kids. Journal of Clinical Child Psychology, 27, 180-189. doi: 10.1207/s15374424jccp2702_5

Central Statistics Office. (2006a). Census 2006 reports. Dublin, Ireland: Stationery Office.

Central Statistics Office. (2006b). EU Survey on Income and Living Conditions. Dublin, Ireland: Stationery Office.

Cohen, J. (1988). Statistical power for the behavioral sciences. Hillsdale, NJ: Erlbaum.

Collishaw, S., Maughan, B., Goodman, R., \& Pickles, A. (2004). Time trends in adolescent mental health. Journal of Child Psychology and Psychiatry, 45, 1350-1362. doi:10.1111/j.1469-7610.2004.00335.x

Colman, I., Murray, J., Abbott, R. A., Maughan, B., Kuh, D., Croudace, T. J., \& Jones, P. B. (2009). Outcomes of conduct problems in adolescence: 40 year follow-up of national cohort. BMJ: British Medical Journal, 338, 208-211. doi:10.1136/bmj.a2981

Conners, C. K. (1994). The Conners Rating Scales: Use in clinical assessment, treatment planning and research. In M. Maruish (Ed.), Use of psychological testing for treatment planning and outcome assessment (pp. 550-578). Hillsdale, NJ: Erlbaum.

Corrigan, A. (2002). Social Competence Scale-Parent Version: Grade 1/Year 2 (Fast Track Project Technical Report). Retrieved from http:// www.fasttrackproject.org/techrept/s/scp/scp2tech.pdf

Dionne, R., Davis, B., Sheeber, L., \& Madrigal, L. (2009). Initial evaluation of a cultural approach to implementation of evidence-based parenting interventions in American Indian communities. Journal of Community Psychology, 37, 911-921. doi:10.1002/jcop.20336

Emerson, E., \& Einfield, S. (2010). Emotional and behavioural difficulties in young children with and without developmental delay: A bi-national perspective. Journal of Child Psychology and Psychiatry, 51, 583-593. doi:10.1111/j.1469-7610.2009.02179.x

Eyberg, S., \& Pincus, D. (1999). Eyberg Child Behavior Inventory and Sutter-Eyberg Student Behavior Inventory—Revised: Professional manual. Odessa, FL: Psychological Assessment Resources.

Fergusson, D. M., Horwood, L. J., \& Ridder, E. M. (2005). Show me the child at seven: The consequences of conduct problems in childhood for psychosocial functioning in adulthood. Journal of Child Psychology, Psychiatry, and Allied Disciplines, 46, 837-849. doi:10.1111/j.14697610.2004.00387.x

Frick, P. J., \& Morris, A. S. (2004). Temperament and developmental pathways to severe conduct problems. Journal of Clinical Child and Adolescent Psychology, 33, 54-68. doi:10.1207/S15374424JCCP3301_6

Furlong, M., \& McGilloway, S. (in press). The Incredible Years Parenting Program in Ireland: A qualitative analysis of the experience of parents living in disadvantaged areas. Clinical Child Psychology and Psychiatry.

Furlong, M., McGilloway, S., Bywater, T., Hutchings, J., Donnelly, M., \& Smith, S. M. (in press). Behavioral/cognitive-behavioral group-based parenting programmes for children aged 3-12 with early onset conduct problems. Cochrane Database of Systematic Reviews.

Furlong, M., McGilloway, S., Bywater, T., Hutchings, J., Donnelly, M., Smith, S. M., \& O’Neill, C. (2010). Behavioural/cognitive-behavioural group-based parenting interventions for children age 3-12 with early onset conduct problems [Protocol]. Cochrane Database of Systematic Reviews, 2010(1), Article CD008225. doi:10.1002/14651858.CD008225 
Gardner, F., Burton, J., \& Klimes, I. (2006). Randomised controlled trial of a parenting intervention in the voluntary sector for reducing child conduct problems: Outcomes and mechanisms of change. Journal of Child Psychology and Psychiatry, 47, 1123-1132. doi:10.1111/j.14697610.2006.01668.x

Gardner, F., Hutchings, J., Bywater, T., \& Whitaker, C. (2010). Who benefits and how does it work? Moderators and mediators of outcomes in an effectiveness trial of a parenting intervention. Journal of Clinical Child and Adolescent Psychology, 39, 568-580. doi:10.1080/ 15374416.2010.486315

Goodman, R. (1997). The Strengths and Difficulties Questionnaire: A research note. Journal of Child Psychology, Psychiatry, and Allied Disciplines, 38, 581-586. doi:10.1111/j.1469-7610.1997.tb01545.x

Haase, T., \& Pratschke, J. (2008). New measures of deprivation for the Republic of Ireland. Dublin, Ireland: Pobal.

Halpenny, A. M., Nixon, E., \& Watson, D. (2009). Summary report on parents' and children's perspectives on parenting styles and discipline in Ireland. Dublin, Ireland: Office of the Minister for Children and Youth Affairs.

Hollis, S., \& Campbell, F. (1999). What is meant by intention to treat analysis? Survey of published randomised controlled trials. British Medical Journal, 319, 670-674.

Hutchings, J., Bywater, T., \& Daley, D. (2007). Early prevention of conduct disorder: How and why did the North and Mid Wales Sure Start study work? Journal of Children's Services, 2, 4-14.

Hutchings, J., Bywater, T., Daley, D., Gardner, F., Whitaker, C., Jones, K., ... Edwards, R. T. (2007). Parenting intervention in Sure Start services for children at risk of developing conduct disorder: Pragmatic randomised controlled trial. BMJ: British Medical Journal, 334, 678-685. doi:10.1136/bmj.39126.620799.55

Jaccard, J., \& Turrisi, R. (2003). Interaction effects in multiple regression (2nd ed). Thousand Oaks, CA: Sage.

Kaminski, J. W., Valle, L. A., Filene, J. H., \& Boyle, C. L. (2008). A meta-analytic review of components associated with parent training program effectiveness. Journal of Abnormal Child Psychology, 36, 567-589. doi:10.1007/s10802-007-9201-9

Kling, A., Forster, M., Sundell, K., \& Melin, L. (2010). A randomized controlled effectiveness trial of parent management training with varying degrees of therapist support. Behavior Therapy, 41, 530-542. doi: 10.1016/j.beth.2010.02.004

Ladd, G. W., Birch, S. H., \& Buhs, E. S. (1999). Children's social and scholastic lives in kindergarten: Related spheres of influence? Child Development, 70, 1373-1400. doi:10.1111/1467-8624.00101

Larsson, B., Fossum, S., Clifford, G., Drugli, M., Handegård, B., \& Mørch, W. (2009). Treatment of oppositional defiant and conduct problems in young Norwegian children. European Child \& Adolescent Psychiatry, 18, 42-52. doi:10.1007/s00787-008-0702-z

Larzelere, R. E., Cox, R. R., \& Smith, G. L. (2010). Do non-physical punishments reduce antisocial behaviour more than spanking? A comparison using the strongest previous causal evidence against spanking. BMC Paediatrics, 10, 10-17. doi:10.1186/1471-2431-10-10

Loeber, R., \& Farrington, D. P. (Eds.). (2001). Child delinquents: Development, intervention, and service needs. Thousand Oaks, CA: Sage.

Lundahl, B., Risser, H. J., \& Lovejoy, M. C. (2006). A meta-analysis of parent training: Moderators and follow-up effects. Clinical Psychology Review, 26, 86-104. doi:10.1016/j.cpr.2005.07.004

Mihalic, S., Fagan, M., Irwin, K., Ballard, D., \& Elliot, D. (2002). Blueprints for Violence Prevention: Factors for implementation success (Report BP-IMP). Boulder, CO: University of Colorado at Boulder, Institute of Behavioral Science, Center for the Study and Prevention of Violence.

National Institute for Health and Clinical Excellence. (2006). Parenttraining/education programmes in the management of children with conduct disorders (NICE Technology Appraisal Guidance 102). Re- trieved from http://guidance.nice.org.uk/nicemedia/live/11584/33426/ 33426.pdf

O’Neill, D., McGilloway, S., Donnelly, M., Bywater, T., \& Kelly, P. (in press). A cost-effectiveness analysis of the Incredible Years parenting programme in reducing childhood health inequalities. European Journal of Health Economics. Advance online publication. doi:10.1007/s10198011-0342-y

Patterson, J., Barlow, J., Mockford, C., Klimes, I., Pyper, C., \& StewartBrown, S. (2002). Improving mental health through parenting programs: Block randomised controlled trial. Archives of Disease in Childhood, 87, 472-477. doi:10.1136/adc.87.6.472

Paulussen-Hoogeboom, M. C., Stams, G. J. J. M., Hermanns, J. M. A., Peetsma, T. T. D., \& van den Wittenboer, G. L. H. (2008). Parenting style as a mediator between children's negative emotionality and problematic behavior in early childhood. Journal of Genetic Psychology, 169, 209-226. doi:10.3200/GNTP.169.3.09-226

Reid, M. J., Webster-Stratton, C., \& Baydar, N. (2004). Halting the development of conduct problems in Head Start children: The effects of parent training. Journal of Clinical Child and Adolescent Psychology, 33, 279-291. doi:10.1207/s15374424jccp3302_10

Reid, M. J., Webster-Stratton, C., \& Hammond, M. (2003). Follow-up of children who received the Incredible Years intervention for oppositional-defiant disorder: Maintenance and prediction of 2-year outcome. Behavior Therapy, 34, 471-491. doi:10.1016/S00057894(03)80031-X

Reid, R., Gonzalez, J. E., Nordness, P. D., Trout, A., \& Epstein, M. H. (2004). A meta-analysis of the academic status of students with emotional/behavioral disturbance. Journal of Special Education, 38, 130143. doi:10.1177/00224669040380030101

Reyno, S. M., \& McGrath, P. J. (2006). Predictors of parent training efficacy for child externalising behavior problems: A meta-analytic review. Journal of Child Psychology and Psychiatry, 47, 99-111. doi: 10.1111/j.1469-7610.2005.01544.X

Robinson, E. A., \& Eyberg, S. M. (1981). The Dyadic Parent-Child Interaction Coding System: Standardization and validation. Journal of Consulting and Clinical Psychology, 49, 245-250. doi:10.1037/0022006X.49.2.245

Schulz, K. F., Altman, D. G., \& Moher, D., for the CONSORT Group. (2010). CONSORT 2010 statement: Updated guidelines for reporting parallel group randomised trials. BMJ: British Medical Journal, 23, 340. doi:10.1136/bmj.c332

Scott, S., Spender, Q., Doolan, M., Jacobs, B., \& Aspland, H. (2001). Multicentre controlled trial of parenting groups for child antisocial behaviour in clinical practice. BMJ: British Medical Journal, 323, 194198. doi:10.1136/bmj.323.7306.194

Serketich, W. J., \& Dumas, J. E. (1996). The effectiveness of behavioral parent training to modify antisocial behavior in children: A metaanalysis. Behavior Therapy, 27, 171-186. doi:10.1016/S00057894(96)80013-X

Shaw, D. S., \& Winslow, E. B. (1997). Precursors and correlates of antisocial behavior from infancy to preschool. In D. Stoff, J. Breiling, \& J. D. Maser (Eds.), Handbook of antisocial behavior (pp. 148-158). New York, NY: Wiley.

Trapolini, T., McMahon, C. A., \& Ungerer, J. A. (2007). The effect of maternal depression and marital adjustment on young children's internalizing and externalizing behaviour problems. Child: Care, Health, and Development, 33, 794-803. doi:10.1111/j.1365-2214.2007.00739.x

Varnell, S. P., Murray, D. M., Jenega, M. S., \& Blitstein, J. L. (2004). Design and analysis of group-randomised trials: A review of recent practices. American Journal of Public Health, 94, 393-399. doi: 10.2105/AJPH.94.3.393

Wasserman, G. A., Keenan, K., Tremblay, R. E., Coie, J. D., Herrenkohl, T. I., Loeber, R., \& Petechuk, D. (2003). Risk and protective factors of child delinquency (NCJ 193409). Washington, DC: U.S. Department of 
Justice, Office of Justice Programs, Office of Juvenile Justice and Delinquency Prevention.

Webster-Stratton, C. S. (1998). Parent training with low income families: Promoting parental engagement through a collaborative approach. In J. R. Lutzker (Ed.), Handbook of child abuse research and treatment: Issues in clinical child psychology (pp. 183-210). New York, NY: Plenum Press.

Webster-Stratton, C. S. (2005). The Incredible Years: A training series for the prevention and treatment of conduct problems in young children. In P. S. Jensen \& E. D. Hibbs (Eds.), Psychosocial treatments for child and adolescent disorders: Empirically based strategies for clinical practice (2nd ed., pp. 507-555). Washington, DC: American Psychological Association.

Webster-Stratton, C., Kolpacoff, M., \& Hollinsworth, T. (1988). Selfadministered videotape therapy for families with conduct-problem children: Comparison with two cost-effective treatments and a control group. Journal of Consulting and Clinical Psychology, 56, 558-566. doi:10.1037/0022-006X.56.4.558
Webster-Stratton, C., \& Reid, M. J. (2010). The Incredible Years Parents, Teachers and Children Training Series: A multifaceted treatment approach for young children with conduct problems. In J. Weisz \& A. Kazdin (Eds.), Evidence-based psychotherapies for children and adolescents (2nd ed., pp. 194-210). New York, NY: Guilford Press.

Webster-Stratton, C., Reid, M. J., \& Hammond, M. (2004). Treating children with early-onset conduct problems: Intervention outcomes for parent, child, and teacher training. Journal of Clinical Child and Adolescent Psychology, 33, 105-124. doi:10.1207/S15374424JCCP3301_11

Williams, J., Greene, S., Doyle, E., Harris, E., Layte, R., McCoy, S., ... Thornton, M. (2009). Growing Up in Ireland: The lives of nine-year olds [Executive summary]. Dublin, Ireland: Stationery Office.

Received November 2, 2010

Revision received September 13, 2011

Accepted September 19, 2011

\section{Online First Publication}

APA-published journal articles are now available Online First in the PsycARTICLES database. Electronic versions of journal articles will be accessible prior to the print publication, expediting access to the latest peer-reviewed research.

All PsycARTICLES institutional customers, individual APA PsycNET ${ }^{\circledR}$ database package subscribers, and individual journal subscribers may now search these records as an added benefit. Online First Publication (OFP) records can be released within as little as 30 days of acceptance and transfer into production, and are marked to indicate the posting status, allowing researchers to quickly and easily discover the latest literature. OFP articles will be the version of record; the articles have gone through the full production cycle except for assignment to an issue and pagination. After a journal issue's print publication, OFP records will be replaced with the final published article to reflect the final status and bibliographic information. 